\section{British civil plutonium}

Sir-Barnham, Hart, Nelson and Stevens (Nature 317,$213 ; 1985$ ) conclude that at least $2.3 \pm 0.8$ tonnes of plutonium produced by the magnox nuclear stations of the UK generating boards cannot be accounted for, and may have been diverted to weapons use. An earlier version of this paper was submitted by the Campaign for Nuclear Disarmament (CND) to the Sizewell B Public Inquiry where it was debated at length. The Central Electricity Generating Board (CEGB) demonstrated that the analysis was in substantial error and no credence could be placed on its conclusions or, of course, the implications that the authors were striving to secure therefrom. While the revised paper takes account of some of the comments made by CEGB, the main criticisms still apply These are as follows.

(1)The paper derives the estimate of 2.3 tonnes by attempting to calculate the total plutonium from the CEGB and South of Scotland Electricity Board (SSEB) stations since 1963, and compares this estimate of 47 tonnes with the amount the government has accounted for in parliamentary statements, augmented by the amounts the authors estimate to be in civil use in the United States, and to have been lost in reprocessing. Since the approach depends on estimating the difference between two large numbers, the conclusion is critically dependent on the accuracy of the calculations - clearly the calculation of plutonium production needs to be accurate to better than 5 per cent for the claimed discrepancy to be of any significance. It follows that a very careful calculation is needed, but although the paper claims an accuracy of \pm 2 per cent, this is not substantiated. In particular, an accurate estimate is needed of the plutonium production as a function of irradiation; this requires calculations for each station using detailed data on station design and operation, and a theoretical model more complex than the simplified method adopted in the paper, which uses approximate data culled from a variety of sources. Since the three different methods of calculation described in the paper all use the same estimate of plutonium production as a function of fuel irradiation (the function $G(B)$. The degree of agreement between their results provides no evidence on the accuracy with which this plutonium pro-

(2)The authors attempt to validate their overall method of calculation by comparover a 6-year period with data provided by CEGB for amounts of plutonium in irradiated fuel despatched for reprocessing from each of our eight magnox stations. Table 4 of the paper concludes that this shows that their model underestimates necessary to obtain results of the accuracy the three methods are not independent. duction function has been calculated. ing estimates of plutonium production plutonium production by 3.7 per cent, implying that their estimate of $2.3 \pm 0.8$ tonnes for plutonium unaccounted for is an underestimate by $0.037 \times 47=1.7$ tonnes. However, as CEGB explained at the Sizewell Inquiry, this comparison is not valid because it does not allow for changes in the level of irradiated fuel stocks at the stations over the six-year period. The comparison is also selective since the paper reports the comparison for seven of the stations but excludes the data provided for the other station at Wylfa. If Wylfa is included, the results are substantially changed - the overall ratio of plutonium dispatches to calculated production changes from 1.037 to 0.948 . If the authors had not excluded the data for Wylfa, they would presumably have concluded that the comparison shows their method over estimates plutonium production by 5.2 per cent and that the claimed discrepancy of $2.3 \pm 0.8$ tonnes is overestimated by 2.4 tonnes.

The board is not able to publish a definitive analysis of plutonium production for reasons that were explained at the Sizewell Inquiry. These relate to the period before 1971 when some of the plutonium produced, although itself remaining in civil use, was bartered with the United States for a quantity of highly enriched uranium which was used for defence purposes. It has been the policy of goverments over the years not to disclose this figure, and we are also precluded from providing detailed information which would help others to derive it.

To sum up, the accuracy of the authors' calculations is not sufficient to support the allegation that plutonium produced in civil reactors in the United Kingdom may have been diverted to weapons use.

Repeated statements in Parliament by ministers have confirmed that no plutonium produced in CEGB reactors has been used for military purposes in the United Kingdom or exported for use in weapons. The government has also stated that it has no plans to use plutonium produced in the board's reactors for nuclear weapons and this is also the policy of the US government.

T.BROOM

\section{Technology, Planning}

and Research Division,

Central Electricity Generating Board,

Courtenay House, 18 Warwick Lane.

London EC4P 4EB, UK

\section{Free will}

SIR-Nothing is gained by the invocation by D. H. Evans (Nature 307. 762; 1985) of the second law of hydrodynamics.

It may be true that free will implies the ability to think divergently; but determinism does not imply convergent thought: it implies only determinism. Given that the thought processes of the scientist are the result only of causes in his environment, they can appear as convergent or divergent. They are convergent when the observer (who is also determined) perceives nothing new (in Evans' terms, no loss of entropy) which could not have been They are divergent when the observer perceives something new (either not deducible or apparently unrelated) which can subsequently be demonstrated by experiment. However, an observer with access to all the facts (that is, the whole internal and external environment of the scientist) might perceive the deductive logic of "divergent" thought.

Free will implies that the scientist has control over his divergent thought (which is intuitively absurd) while determinism implies only cause and effect. Convergence and divergence are then functions of the observer's environment, not the scientist's environment.

The entropy of the situation is more straightforward. Entropy is different in spatial and temporal regions of the Universe, and the variability might arise as a result of local fluctuations and aggregations. Given a spectrum of entropy, its value in one region is a statistical function (deterministically predictable but otherwise chosen (!)) and in any given region can be very high or very low. Thus in the spatial regions of living forms it can be very low: temporally it may continue to fall before it rises again.

Consciousness may indeed be a manthe brain may function far from thermodynamic equilibrium: but that does not way that a whirlpool is determined.

S.J.Starkie

8 Weston Grove,

Fulbourn, Cambridge, UK

\section{Academic tenure}

SIR-The question whether those who work as professors or researchers at academic institutions should enjoy security of tenure has been much discussed (see, for example, Nature 317, 464; 1985) but surely, in democracies, if job security is to be eroded for some, the same rules should apply to others. Yet in the armed services, those who graduate from military academies and similar institutions have tenure for the rest of their lives. They may be asked to retire early but are compensated with a pension, and at no point are they required to justify their promotion. largely automatic, by enumerating the battles they have won or the missiles they have fired accurately, the military equivalents of papers published or graduate students trained. Can this be fair?

Clavecimbellaan 273

J.M. Goldschvartz deduced logically from the observed facts. ifestation of biochemical processes, and prevent it being determined in the same

The Netherlands 